\title{
Percutaneous Endoscopic Lumbar Discectomy for Athletes
}

Koichi Sairyo', Tetsuya Matsuura1', Kosaku Higashino', Toshinori Sakai', Naoto Suzue', Daisuke Hamada', Tomohiro Goto', Yoichiro Takata', Toshihiko Nishisho', Yuichiro Goda'1, Ryosuke Sato', Ichiro Tonogai', Fumitake Tezuka', Kazuaki Mineta' and Akira Dezawa ${ }^{2}$

${ }^{1}$ Department of Orthopedics, The University of Tokushima, Tokushima, Japan

${ }^{2}$ Department of Orthopedic Surgery, Teikyo University Mizonokuchi Hospital, Japan

\section{Abstract}

Study design: Retrospective review of multiple cases.

Objectives: To understand the effectiveness of Percutaneous Endoscopic Discectomy (PED) for athletes.

Summary of background data: PED was first performed in 2002 and showed good clinical outcome for normal subjects. However, there are few reports for athletes.

Methods: Ten male athletes with herniated nucleus pulposus underwent PED surgery under local anesthesia Operation time, blood loss, and surgery-related complications were recorded. Changes in Visual Analog Scale (VAS) scores for low back pain and leg pain before and after surgery were reviewed. Time to return to play (RTP), RTP rate, and recurrence were also evaluated.

Results: Herniated fragments were successfully removed endoscopically. Mean operation time was 53.5 min, blood loss during operation was negligible, and no surgery-related complications such as dural tear, nerve root injury, hematoma, or surgical site infection were observed. Subjects returned to their sport 6 to 8 weeks after surgery. The mean VAS score (out of 10 ) for low back and leg pain was 0.5 and 0 , respectively at the final follow-up, compared with 6.5 and 4.5 before surgery. Of the patients, $9(90 \%)$ had complete RTP, and one $(10 \%)$ showed recurrence.

Conclusions: The minimal invasiveness and good clinical outcome of PED favor it as a gold standard for disc surgery in athletes.

Keywords: Percutaneous Endoscopic Discectomy (PED); Anesthesia; Visual Analog Scale (VAS)

\section{Introduction}

The percutaneous spinal endoscopic technique was developed by Yeung and Tsou [1,2] for lumbar herniated nucleus pulposus (HNP) and is known as percutaneous endoscopic discectomy (PED). Originally, Hijikata [3] developed percutaneous discectomy without using a spinal endoscope. Then, PED surgery was developed based on Hijikata's technique. A standard intracanal HNP can be removed using the transforaminal approach, except at the level of L5-S1, which requires the interlaminar approach [4-7]. An extracanal HNP can be removed using a posterolateral approach $[1,2,8]$. Even with the challenging space in HNP surgery, known as the 'hidden zone', PED can be applied to remove the fragment [9]. The most powerful advantage of PED, however, is that it is conducted under local anesthesia.

PED is performed under local anesthesia and requires an 8-mm skin incision. PED is the least invasive disc surgery procedure, especially for back muscles; thus, it is also theoretically the best approach for athletes. However, there are few reports in the literature on PED surgery for athletes. In the past 2 years, 10 very active athletes underwent PED surgery at our institution. Here, we review the clinical outcome of these cases.

\section{Methods}

From April 1, 2010 to April 1, 2012, 10 male athletes aged from 17 to 57 visited our sports clinic because of low back pain. Nine players were top-class national athletes. The other was a high school student. Patient characteristics are displayed in Table 1. Magnetic resonance imaging (MRI) revealed HNP in the lumbar spine in all cases. The affected level was L2-L3 ( $\mathrm{n}=1)$, L3-L4 $(\mathrm{n}=1)$, and L4-L5 $(\mathrm{n}=8)$. One patient (case \#4) had far-lateral disc herniation at L4-L5, and the remaining nine patients showed intracanal type HNP.

\section{Surgery}

The posterolateral approach was used for the far-lateral case, while the transforaminal approach was used for the remaining intracanaltype HNPs. Local anesthesia (1\% lidocaine) was used for all cases, and $10-20 \mathrm{ml}$ of lidocaine proved generally sufficient for the entire procedure. Figure 1 illustrates the PED technique. The HNP was removed percutaneously through an $8-\mathrm{mm}$ cannula, as shown in the left panel. Consequently, the skin incision scar was very small $(8 \mathrm{~mm})$, as noted in the right panel.

Subjects were followed for at least 6 months after surgery ( 6 to 26 months). We clinically reviewed pre and post-operative visual analog

\begin{tabular}{|l|l|l|c|}
\hline Case \# & Age & Sport & HNP level \\
\hline$\# 1$ & 34 & Soccer, Professional & $\mathrm{L} 4 / 5$ \\
\hline$\# 2$ & 32 & American football, top amateur & $\mathrm{L} 4 / 5$ \\
\hline$\# 3$ & 17 & Boat race, high school & $\mathrm{L} 4 / 5$ \\
\hline$\# 4$ & 56 & Golf, top amateur & $\mathrm{L} 4 / 5$ \\
\hline$\# 5$ & 22 & Discus thrower, college & $\mathrm{L} 4 / 5$ \\
\hline$\# 6$ & 22 & American football, college & $\mathrm{L} 4 / 5$ \\
\hline$\# 7$ & 34 & Baseball, Professional & $\mathrm{L} 4 / 5$ \\
\hline$\# 8$ & 20 & American football, college & $\mathrm{L} 4 / 5$ \\
\hline$\# 9$ & 27 & American football, top amateur & $\mathrm{L} 3 / 4$ \\
\hline$\# 10$ & 10 & Handball, college & $\mathrm{L} 2 / 3$ \\
\hline & & Table 1: Subject characteristics. & \\
\hline
\end{tabular}

*Corresponding author: Koichi Sairyo, Professor \& Chairman, Department of Orthopedics, The University of Tokushima, 3-18-15, Kuramoto, Tokushima 770-8503 Japan; Tel: +81-88-633-7240, Fax: +81-88-633-0178; E-mail: sairyokun@hotmail.com

Received October 16, 2013; Accepted October 21, 2013; Published October 24, 2013

Citation: Sairyo K, Matsuura T, Higashino K, Sakai T, Suzue N, et al. (2013) Percutaneous Endoscopic Lumbar Discectomy for Athletes. J Spine S5: 006. doi:10.4172/2165-7939.S5-006

Copyright: $\odot 2013$ Sairyo K, et al. This is an open-access article distributed under the terms of the Creative Commons Attribution License, which permits unrestricted use, distribution, and reproduction in any medium, provided the original author and source are credited. 
Citation: Sairyo K, Matsuura T, Higashino K, Sakai T, Suzue N, et al. (2013) Percutaneous Endoscopic Lumbar Discectomy for Athletes. J Spine S5: 006. doi:10.4172/2165-7939.S5-006

Page 2 of 4

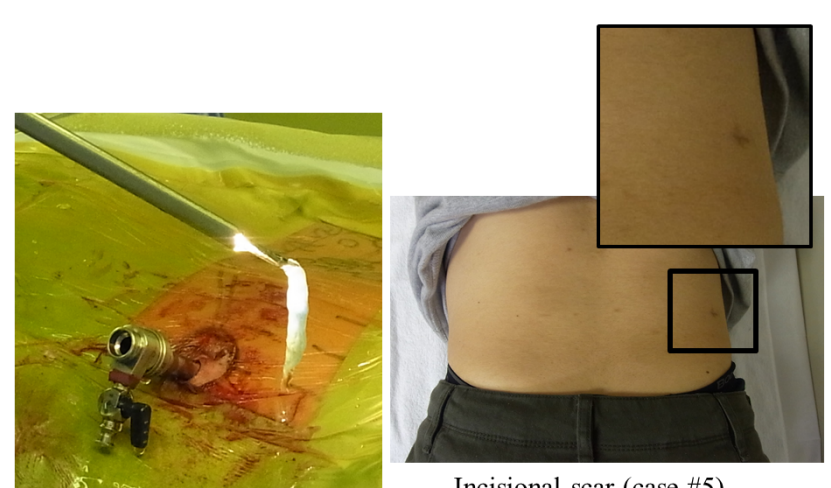

Incisional scar (case \#5)

Figure 1: Percutaneous endoscopic discectomy (PED) and incisional scar. Left panel: A large fragment of herniated nucleus pulposus (HNP) is removed through an 8-mm cannula. Right panel: Incisional scar for the transforaminal approach.

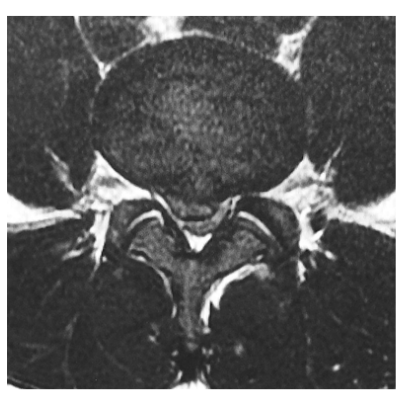

(A) Before OP

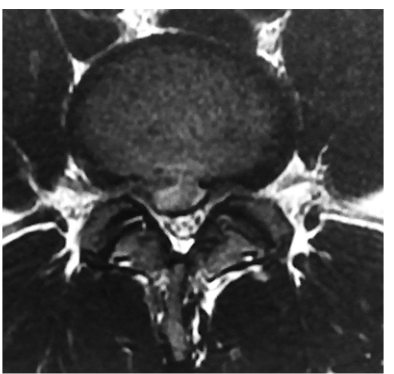

(C) At the recurrence

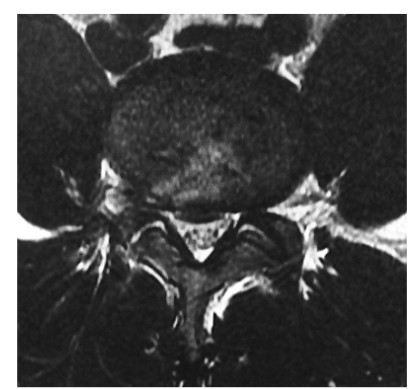

(B) 1 month after OP

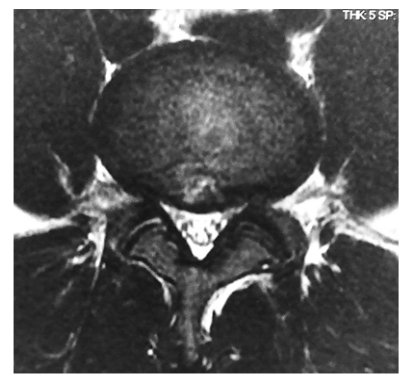

(D) Final follow-up
Figure 2: Case \#6 showing recurrence of HNP. 2-a: Axial magnetic resonance imaging (MRI) before surgery. 2-b: Axial MRI after surgery. The HNP fragment was removed by PED. 2-c: Axial MRI at the time of HNP recurrence. A HNP recurrence mass with high signal is present. 2-d: The final MRI showing regression of the HNP mass.

scale (VAS) scores for low back pain and leg pain. MRI was conducted before and at 3 months after surgery.

\section{Results}

For all 10 cases, HNPs were successfully removed by PED under local anesthesia. Mean operation time was 53.5 min (range, 43 to 75 $\mathrm{min}$ ). Blood loss during operation was negligible, and no surgeryrelated complications such as dural tear, nerve root injury, hematoma, or surgical site infection were observed.

Seven days after surgery, subjects started active stretching for tight hamstrings and isometric trunk exercises. One month later, jogging was allowed. At the time, mean VAS score (out of 10) for low back pain and leg pain was 0.5 and 0 , respectively, compared with 6.5 and 4.5 , respectively before surgery. Only one case (case \#8) had low back pain at final follow-up. Participation in active sports was resumed 6 to 8 weeks after surgery. Time to return to play (RTP) is shown in Table 2 . All 10 subjects were able to return to their original sport, and nine were able to return at their original competitive level. Case \#8 returned to his original sport but could not perform at $100 \%$ due to mild back pain. Case \#5 returned to his original sport 5 weeks after surgery because he strongly wished to attend a national intercollege competition. Since his sport was discus throw--a non-contact activity--he was allowed to return early, and he experienced no recurrence at his final follow-up (12 months after surgery). Otherwise, we advised the other players not to return to their sport for at least 6 weeks after surgery.

Only one player (case \#6) showed recurrence after returning to his sport. Figure $2 \mathrm{a}$ shows axial MRI of case \#6 before surgery. The HNP mass was removed using the transforaminal approach (Figure 2b). Four weeks after surgery, the VAS score was 0 for both low back pain and leg pain, compared with 8 and 2, respectively before surgery. Since his condition was good, we allowed him to return to his sport 6 weeks after surgery. One month after returning to his sport, however, he experienced sudden and severe back pain after being tackled and falling. Figure $2 \mathrm{c}$ shows axial MRI at that time. Recurrence of the HNP mass with high signal was noted. The VAS score was 7 for back pain and 4 for leg pain. In addition, he complained of hypesthesia in the right big toe. After taking a 3-month break, all complaints had disappeared. Figure 2d shows the final MRI; the HNP mass had naturally regressed.

\begin{tabular}{|l|l|c|}
\hline Case \# & Sport & Return to sport ( week) \\
\hline$\# 1$ & Soccer, Professional & 8 \\
\hline$\# 2$ & $\begin{array}{l}\text { American football, top } \\
\text { amateur }\end{array}$ & 8 \\
\hline$\# 3$ & Boat race, high school & 8 \\
\hline$\# 4$ & Golf, top amateur & 8 \\
\hline$\# 5$ & Discus thrower, college & 5 \\
\hline$\# 6$ & American football, college & 6 \\
\hline$\# 7$ & Baseball, Professional & 6 \\
\hline$\# 8$ & American football, college & 8 \\
\hline$\# 10$ & American football, top & 6 \\
\hline & amateur & 8 \\
\hline
\end{tabular}

Table 2: Time to return to play (RTP).

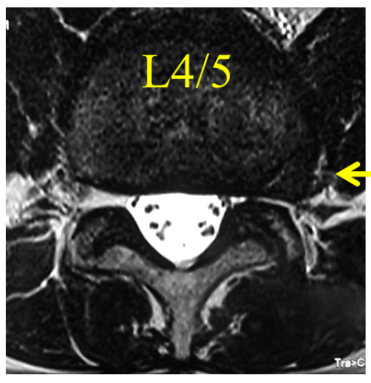

(A) Before OP

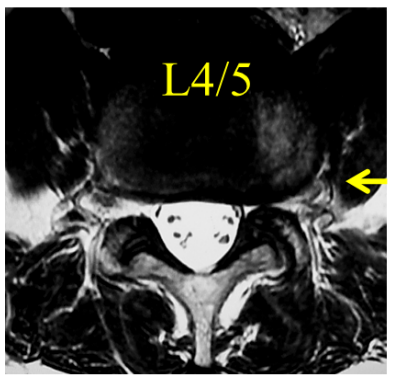

(B) 3 months after OP
Figure 3: MRI of case \#4 showing far lateral HNP at L4-L5. Left panel: The far-lateral HNP mass is compressing the L4 exiting nerve root on the left side. Right panel: The HNP mass is successfully removed using the posterolateral approach of PED. 


\section{Cases Report}

Case \#4 was a 56-year-old golfer and a top amateur player at the national level. He complained of strong leg pain (VAS score, 9/10) and mild back pain (4/10). A far-lateral HNP mass was found compressing the L4 exiting nerve root on the left side (Figure 3, left panel). The HNP mass was successfully removed using the posterolateral approach of PED (Figure 3, right panel). Figure 4 shows the endoscopic view of this case. The herniated mass is shown in blue because we injected indigo intradiscally just before surgery. Color enables the nerve root (red) to be easily distinguished from the HNP mass (blue). Eight weeks after surgery, he returned to golf. At his final follow-up (25 months after surgery), he was very active with golf without recurrence.

Case \#9 was a 27 -year-old American football player, a top player at the national level, and a member of the national team. He played as a placekicker--a non-contact position. He first noticed back pain and right leg pain, which decreased after undergoing 3 months of conservative treatment. However, he also had weakness during right knee extension so was referred to us for surgery. At the initial visit, his low back pain and leg pain was mild (VAS score, 2/10 and 3/10,

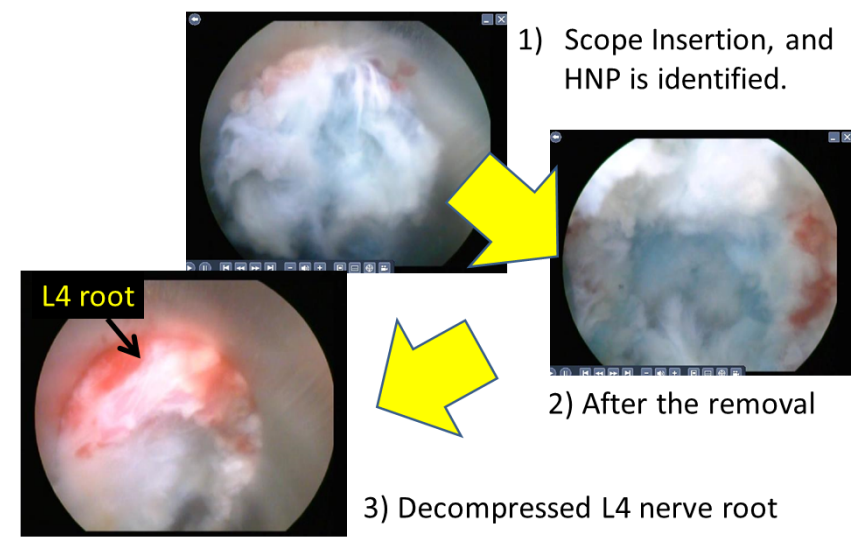

Figure 4: Endoscopic view during surgery in case \#4. The herniated mass is blue because we injected indigo intradiscally just before surgery. Color enables the nerve root (red) to be easily distinguished from the HNP mass.

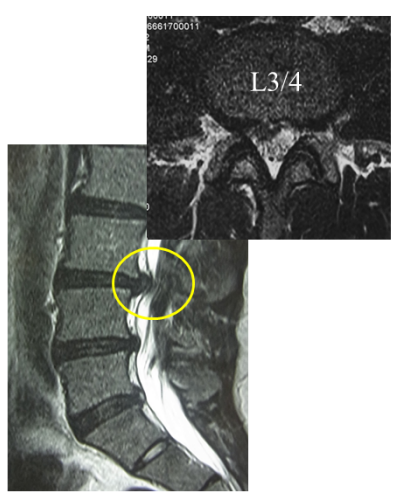

(A) Before OP

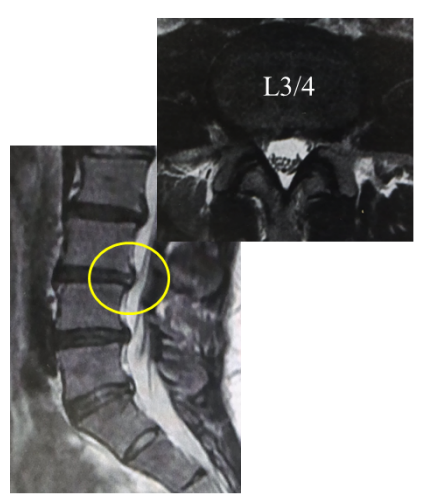

(B) 3 months after OP
Figure 5: MRIs before and after surgery in case \#9. Left panel: HNP at L3-L4, which migrated slightly caudally, is seen before surgery. The HNP fragment was removed by PED under local anesthesia. Right panel: At the final check-up at 6 months after surgery, we confirmed the removal of HNP without any recurrence. respectively). However, manual muscle testing for the right quadriceps femoris indicated weakness at $4 / 5$, and PTR was diminished on the right side. Hypoesthesia was also present along the right L4 dermatome. Subsequently, L4 radiculopathy was diagnosed due to HNP at L3-L4 (Figure 5, left panel). The HNP fragment was removed by PED under local anesthesia. Four week later, back pain and leg pain completely subsided; however, the subject still had weakness. He started jogging and squatting 4 weeks after surgery, and his weakness gradually improved. Six weeks after surgery, he returned to his original sport as his muscle strength had almost recovered, enabling him to perform fully as a kicker. At his final follow-up (6 months after surgery), no recurrence was observed (Figure 5, right panel).

\section{Discussion}

\section{Low invasiveness of PED compared with other techniques}

Surgical intervention is sometimes inevitable when conservative treatment is not effective. In the 20th century, discectomy after laminectomy (known as Love's procedure) was the gold standard. By the late 20th century, attempts to reduce invasiveness were made by using a microscope and an endoscope. In particular, endoscopy enabled low invasiveness, and this approach was termed microendoscopic discectomy (MED) by Detandeau [10] and Foley and Smith [11]. MED requires a $16-\mathrm{mm}$ skin incision to remove HNP by using a similar approach to Love's procedure. In the beginning of the $21^{\text {st }}$ century, an even less-invasive endoscopic procedure--PED--was introduced.

PED is performed under local anesthesia and necessitates an 8 - $\mathrm{mm}$ skin incision, which is half the length of that in MED. Figure 5 illustrates the three approaches of PED. Unlike Love's procedure and MED, using the transforaminal and posterolateral approaches, PED does not damage the back muscles. Even when using the interlaminal approach, invasiveness is notably less than in MED. Thus, PED is clearly a disc surgery approach which is the most minimally invasive for back muscles. For athletes, as low invasiveness of the back muscles is important, PED is the most suitable technique for HNP cases.

\section{Time to RTP}

There is no consensus on RTP in the literature. Watkins et al. [12] applied an organized rehabilitation program for athletes after surgery and reported a mean RTP time of 5.2 months for professional and Olympic athletes who had undergone micro-discectomy. Abla et al. [13] sent a questionnaire to 1000 spine surgeons requesting RTP data for golfers who had undergone spinal surgery. They received 523 responses which revealed that the most common RTP time recommended for golfers after micro-discectomy was 4 to 8 weeks. Yoshida and coworkers reported clinical results of MED in both non-athletes and athletes [14,15]. Invasiveness of the back muscles by MED was reduced compared with Love's procedure and micro- discectomy [15] because MED uses a 16-mm tubular retractor and spinal endoscope. In their study, athletes could return in a relatively short time after surgery [15].

The invasiveness of PED is the lowest of all kinds of discectomy, including Love's procedure, micro-discectomy, and MED. However, our ability to facilitate the return of injured athletes to RTP is limited because the biggest concern after RTP is recurrence. Although approach-related injury to back muscles in PED is the lowest, the discectomy itself is similar to that of other procedures. Furthermore, the time required to heal the injured disc will likely be that same as that seen following other discectomy techniques. Therefore, even though PED is the least invasive approach for disc surgery, the time to RTP is similar to that seen in other approaches at 6 to 8 weeks. 
Citation: Sairyo K, Matsuura T, Higashino K, Sakai T, Suzue N, et al. (2013) Percutaneous Endoscopic Lumbar Discectomy for Athletes. J Spine S5: 006. doi:10.4172/2165-7939.S5-006

Page 4 of 4

\begin{tabular}{|l|l|c|}
\hline Case \# & Sport & HNP level \\
\hline$\# 1$ & Soccer, Professional & 8 \\
\hline$\# 2$ & American football, top amateur & 8 \\
\hline$\# 6$ & American football, college & 6: Recurrence $(+)$ \\
\hline$\# 8$ & American football, college & 8 \\
\hline$\# 10$ & Handball, college & 8 \\
\hline
\end{tabular}

Table 3: Recurrence and time to RTP for contact sport players.

\section{$\mathrm{RTP}$ rate}

RTP is the main purpose for athletes undergoing surgical treatment. Hsu [16] reported the clinical outcome of lumbar discectomy for professional players in the National Football League (NFL). Between 1979 and 2008, 96 players underwent discectomy, and 78\% returned to the NFL. Wang et al. [17] conducted micro-discectomy for elite college athletes who all showed satisfactory recovery from surgery and few symptoms in daily life, with $90 \%$ returning to their original competitive activity. Watkins et al. [12] reviewed the clinical outcome of microscopic discectomy in 60 professional and Olympic athletes. After surgery, $88 \%$ were able to return to their sport at their original competitive level. Anakwenze et al. [18] reviewed the performance outcome of lumbar discectomy conducted between 1991 and 2007 for basketball players in the National Basketball Association (NBA) and found that 18 of 24 were able to return to play in the NBA. In our series, all ten players recovered satisfactorily from surgery; however, one American football player could not return to his original activity because of mild back pain. Thus, the RTP rate for full activity was $90 \%$, which is comparatively better that of previous reports.

\section{Recurrence rate}

The biggest issue after discectomy is HNP recurrence. In the nonathletic population, this rate is around $10 \%$, according to Carragee's report [19]. Hsu [16] reported the clinical outcome after microdiscectomy in 96 professional athletes in the NFL. Eight athletes (8.3\%) showed recurrence with a value similar to that in the non-athletic population. In our series, only 1 of 10 athletes (10\%) showed recurrence after PED, which is similar to that in previous reports.

Case \#6 was a non-contact American football player with recurrence who returned to his sport 6 weeks after surgery. In our series, on the other hand, 5 of 10 subjects played a contact sport (Table 3), and 4 returned to play 8 weeks after surgery. Clearly, time to RTP for athletes in contact sports is difficult to determine.

\section{Limitation}

The small study population of 10 athletes showed that although PED is the least invasive technique for the back muscles, clinical outcome with reference to time to RTP, RTP rate, and recurrence rate is not significantly different compared with other discectomy approaches. We will therefore continue evaluating the outcome of PED in a larger number of patients.

\section{Conclusion}

The minimal invasiveness and good clinical outcome of PED favor it as a gold standard for disc surgery in athletes. However, further investigation with a larger study population is required.

\section{References}

1. Yeung AT (2000) The evolution of percutaneous spinal endoscopy and discectomy: state of the art. Mt Sinai J Med 67: 327-332.

2. Yeung AT, Tsou PM (2002) Posterolateral endoscopic excision for lumbar disc herniation: Surgical technique, outcome, and complications in 307 consecutive cases. Spine (Phila Pa 1976) 27: 722-731.

3. Hijikata S (1989) Percutaneous nucleotomy. A new concept technique and 12 years' experience. Clin Orthop Relat Res: 9-23.

4. Choi G, Lee SH, Raiturker PP, Lee S, Chae YS (2006) Percutaneous endoscopic interlaminar discectomy for intracanalicular disc herniations at L5S1 using a rigid working channel endoscope. Neurosurgery 58: ONS59-68.

5. Ruetten S, Komp M, Merk H, Godolias G (2008) Full-endoscopic interlaminar and transforaminal lumbar discectomy versus conventional microsurgical technique: a prospective, randomized, controlled study. Spine (Phila Pa 1976) 33: 931-939.

6. Dezawa A, Sairyo K (2011) New minimally invasive discectomy technique through the interlaminar space using a percutaneous endoscope. Asian $J$ Endosc Surg 4: 94-98.

7. Koga S, Sairyo K, Shibuya I, Kanamori Y, Kosugi T, et al. (2012) Minimally invasive removal of a recurrent lumbar herniated nucleus pulposus by the small incised microendoscopic discectomy interlaminar approach. Asian J Endosc Surg 5: 34-37.

8. Kitagawa Y, Sairyo K, Shibuya I, Kitahama Y, Kanamori Y, et al. (2012) Minimally invasive and simultaneous removal of herniated intracanal and extracanal lumbar nucleus pulposus with a percutaneous spinal endoscope. Asian J Endosc Surg 5: 183-186.

9. Dezawa A, Mikami H, Sairyo K (2012) Percutaneous endoscopic translaminar approach for herniated nucleus pulposus in the hidden zone of the lumbar spine. Asian J Endosc Surg 5: 200-203.

10. Destandau J (1999) A special device for endoscopic surgery of lumbar disc herniation. Neurol Res 21: 39-42.

11. Foley KT, Smith MM (1997) Microendoscopic discectomy. Tech Neurosurg 3 : 301-307.

12. Watkins RG 4th, Williams LA, Watkins RG 3rd (2003) Microscopic lumba discectomy results for 60 cases in professional and Olympic athletes. Spine J 3: 100-105.

13. Abla AA, Maroon JC, Lochhead R, Sonntag VK, Maroon A, et al. (2011) Return to golf after spine surgery. J Neurosurg Spine 14: 23-30.

14. Nakagawa Y, Yoshida M, Maio K (2006) Microendoscopic discectomy (MED) for surgical management of lumbar disc disease: Technical Note. The Internet Journal of Spine Surgery.

15. Kishi S, Iwabuchi K, Nomura K, Sakai N, Yoshida M (2012) The very early stage rehabilitation program after lumbar discectomy (MED method). Jpn J Orthop Sports Med (in Japanese) 32: 233- 241.

16. Hsu WK (2010) Performance-based outcomes following lumbar discectomy in professional athletes in the National Football League. Spine (Phila Pa 1976) 35: 1247-1251.

17. Wang JC, Shapiro MS, Hatch JD, Knight J, Dorey FJ, et al. (1999) The outcome of lumbar discectomy in elite athletes. Spine (Phila Pa 1976) 24: 570-573.

18. Anakwenze OA, Namdari S, Auerbach JD, Baldwin K, Weidner ZD, et al. (2010) Athletic performance outcomes following lumbar discectomy in professional basketball players. Spine (Phila Pa 1976) 35: 825-828.

19. Carragee EJ, Spinnickie AO, Alamin TF, Paragioudakis S (2006) A prospective controlled study of limited versus subtotal posterior discectomy: Short-term outcomes in patients with herniated lumbar intervertebral discs and large posterior annular defect. Spine (Phila Pa 1976) 31: 653-657. 